\title{
Altered Subcutaneous Adipose Tissue Response to Systemic LPS Administration in Patients with Type 2 Diabetes \\ Mathur $\mathbf{N}^{1}$, Andreasen AS ${ }^{1,2}$, Berg RMG ${ }^{1}$, Pedersen $\mathbf{M}^{1}$, Møller $\mathrm{K}^{1,2,3}$, Pedersen BK ${ }^{1 *}$ and Laye $\mathbf{M J}^{1}$
}

${ }^{1}$ Centre of Inflammation and Metabolism, Department of Infectious Diseases and CMRC, Rigshospitalet, University of Copenhagen, Denmark

${ }^{2}$ Intensive Care Unit 4131, University Hospital Rigshospitalet, Copenhagen, Denmark

${ }^{3}$ Neurointensive Care Unit, Department of Neuroanaesthesiology, University Hospital Rigshospitalet, Copenhagen, Denmark

\begin{abstract}
Aim: Inflammation is thought to play a major role in impaired metabolism. However, the metabolic and inflammatory response of adipose tissue, to a pro-inflammatory stimulus is poorly defined in patients with Type 2 Diabetes Mellitus (T2DM). We therefore aimed to investigate whether adipose tissue in T2DM would display an altered response to $E$. coli LipoPolySaccharide (LPS)

Materials and methods: Twelve patients with T2DM and 12 control subjects received an intravenous bolus injection of LPS $(0.3 \mathrm{ng} / \mathrm{kg})$. Abdominal subcutaneous adipose tissue biopsies, serum and plasma were obtained at $0,2,4,6$ and 8 hours after LPS. The gene expression of Tumour Necrosis Factor- $\alpha$ (TNF), InterLeukin-6 (IL-6), lipoprotein lipase (LPL), hormone sensitive lipase (HSL), fatty acid synthase (FASN), adiponectin and peroxisome proliferator-activated recptor y (PPARy) was analysed by real time reverse transcription Polymerase Chain Reaction (PCR).

Results: The expression of TNF and IL- 6 in adipose tissue increased after LPS administration without any difference between groups (2-way ANOVA, effect of time: $p<0.001$ and $p=0.0001$, respectively). In contrast, the expression of LPL, HSL and adiponectin in adipose tissue increased only in control subjects (2-way ANOVA, effect of time X group: $p=0.03 ; p=0.02$ and $p=0.02$, respectively). There was no effect of LPS on FASN or PPARy in either group.

Conclusion: Patients with T2DM demonstrate a resistance to LPS in terms of inducing important mediators of lipolysis and lipogenesis, although the expression of TNF and IL-6 in adipose tissue increased in both groups. And thus, adipose tissue may contribute to the acute inflammation-related metabolic complications seen in T2DM.
\end{abstract}

Keywords: Endotoxin; Inflammation; Adipogenesis; Adipose tissue; Type 2 diabetes; Adiponectin; Cytokines; Lipolysis; Lipogenesis

Abbreviations: T2DM: Type 2 Diabetes Mellitus; LPS: LipoPolySaccharide; TNF: Tumor Necrosis Factor- $\alpha$; IL-6: InterLeukin-6; LPL: LipoProtein Lipase; HSL: Hormone Sensitive Lipase; FASN: Fatty Acid Synthase; PPARy: Peroxisome ProliferatorActivated Recptor $\gamma$

\section{Introduction}

Patients with T2DM have an increased risk of infectious diseases and sepsis and the overall mortality due to infection is nearly twice as high when compared to non-diabetic patients [1]. We have previously characterised the inflammatory response in plasma and skeletal muscle of patients with T2DM to a low-dose bolus of E. coli LipoPolySaccharide (LPS), a human-experimental model of systemic inflammation [2,3]. Thus, when compared to control subjects with Normal Glucose Tolerance (NGT), patients with T2DM exhibit attenuated Tumour Necrosis Factor-Alpha (TNF) and InterLeukin (IL)-6 responses. The LPS-induced increase in skeletal muscle NF- $\mathrm{kB}$ binding activity and JNK phosphorylation are furthermore enhanced, whereas the gene expression of cytokines was unchanged. The phosphorylation of Adenosine Monophosphate-Activated Protein Kinase (AMPK), a major player in the regulation of cellular glucose uptake, was furthermore increased in the NGT group, but not in T2DM patients [3]. Compared to control subject's patients with T2DM may thus have both an impaired ability to respond to pathogen-associated molecular patterns, such as LPS, and be more prone to develop dysregulated glucose disposal in the context of systemic inflammation [3].
A mounting volume of evidence suggests that adipose tissue functions as an endocrine organ that is capable of secreting mediators that act both locally and systemically $[4,5]$. However, the inflammatory response of subcutaneous adipose tissue has been only scarcely investigated, but adipose tissue dysfunction may contribute to obesityinduced chronic inflammation, which in turn results in metabolic disorders such as impaired glucose tolerance and type 2 diabetes [4] Moreover, since acute inflammation triggers the release of free fatty acids from adipocytes, which involves the paracrine and endocrine secretome within adipose tissue [6], free fatty acids may modify the inflammatory response and contribute to the development of insulin resistance during systemic inflammation [7]. In addition, cytokines/ adipokines released from adipose tissue may affect lipid metabolism, glucose storage and inflammation. Apart from resident macrophages in adipose tissue, adipocytes per se may be able to produce cytokines upon proinflammatory stimuli $[6,8]$.

${ }^{*}$ Corresponding author: Bente Klarlund Pedersen, Centre of Inflammation and Metabolism, Rigshospitalet- Section 7641, Blegdamsvej 9, DK-2100, Copenhagen, Denmark, Tel: +45 354577 97; Fax: +45 354576 44; E-mail: bkp@rh.dk

Received August 16, 2012; Accepted October 11, 2012; Published October 17, 2012

Citation: Mathur N, Andreasen AS, Berg RMG, Pedersen M, Møller K, et al. (2012) Altered Subcutaneous Adipose Tissue Response to Systemic LPS Administration in Patients with Type 2 Diabetes. J Diabetes Metab 3: 217. doi:10.4172/2155 6156.1000217

Copyright: @ 2012 Mathur N, et al. This is an open-access article distributed unde the terms of the Creative Commons Attribution License, which permits unrestricted use, distribution, and reproduction in any medium, provided the original author and source are credited. 
In the present study we hypothesized that the adipose tissue response to a pro-inflammatory stimulus may influence whole-body metabolism and that this response is specifically impaired in patients with T2DM. We thus expected patients with T2DM to exhibit an attenuated LPSinduced increase in the gene expression of inflammatory, lipolytic, and lipogenic mediators within adipose tissue when compared to NGT control subjects.

\section{Material and Methods}

\section{Ethical approval}

This study was approved by the scientific ethical committee of Copenhagen and Frederiksberg Municipalities (KF 01-320695). The trial was registered with ClinicalTrials.gov (Registration Number: NCT 00412906) and the study conformed to the latest revision of the Declaration of Helsinki.

\section{Subjects}

From a larger intervention study [2], a subset of 12 male subjects with T2DM and 12 age-matched male subjects with normal glucose tolerance (controls) were retrospectively selected. After ethical approval and informed consent, each subject underwent a physical examination including blood sampling for general medical screening and a fitness test. The presence or absence of T2DM was determined by a 2-hour Oral Glucose Tolerance Test (OGTT) in accordance with the WHO classification criteria [9]. Exclusion criteria were symptoms or medical history of cardiovascular, pulmonary, renal or autoimmune diseases, as well as treatment with insulin, systemic anti-inflammatory drugs, anticoagulants, ACE-inhibitors or angiotensin II-antagonist. Diabetesrelated medications, including statins, were withheld for seven days prior to the study; all other types of medication were withheld for $24 \mathrm{~h}$ before the study day [2]. No volunteer experienced fever or any other symptom of infection during the 14 days preceding the study day.

\section{Oral glucose tolerance test}

Following baseline venous blood samples, subjects drank 500 $\mathrm{ml}$ of water containing $75 \mathrm{~g}$ of dissolved glucose, and blood samples for measurement of plasma glucose were collected after 60 and 120 minutes.

\section{LPS administration}

The LPS experimental design has been described previously [10]. Briefly, peripheral IV catheters were placed in an antecubital vein bilaterally for blood sampling and the administration of LPS and fluids. Heart rate, noninvasive blood pressure and peripheral oxygen saturation were continuously monitored. An intravenous bolus injection of $E$. coli LPS was administered at a dose of $0.3 \mathrm{ng} / \mathrm{kg}$ after baseline blood samples and a subcutaneous adipose tissue biopsy had been obtained.

\section{Blood samples}

Blood samples for measurement of adiponectin and free fatty acids were drawn at baseline and hourly until $8 \mathrm{~h}$ after LPS administration by spinning of whole blood, drawn into tubes either containing EDTA or Serum Sep Clot Activator, at $3500 \mathrm{rpm}$ for $15 \mathrm{~min}$ at $4^{\circ} \mathrm{C}$. Plasma and serum samples were stored at $-80^{\circ} \mathrm{C}$ until further analyses. Total adiponectin serum concentrations were determined in duplicate by using an MSD Human ElectroChemiLuminescent (ECL) assay (MESO Scale Discovery, USA, Maryland, cat. No.K151BXC-1) and mean concentrations were calculated. Plasma free fatty acids concentrations were determined by a commercially available kit (Wako Chemicals, Germany, cat. No. 999-75406).

\section{Subcutaneous adipose biopsy}

After anaesthetising ( $2 \mathrm{ml}$ Lidocain 2\%) the skin on the abdomen near the umbilicus, $\sim 100 \mathrm{mg}$ subcutaneous adipose tissue was extracted with a Bergstrom biopsy needle under sterile conditions at time points $0,2,4,6$ and 8 hours post LPS administration. Subcutaneous adipose tissue biopsies were rinsed with sterile saline, removed of any visible vasculature, frozen in liquid nitrogen, and stored at $-80^{\circ} \mathrm{C}$ until analyzed.

\section{RNA isolation and qPCR}

Adipose tissue samples were homogenised (approximately $60 \mathrm{mg}$ subcutaneous adipose tissue) in $1 \mathrm{~mL}$ of Trizol (Invitrogen, USA) using a Tissuelyzer (Qiagen, Retsch GmbH, Germany). Total RNA was isolated from adipose tissue according to the manufacturer's protocol (Invitrogen, Carlsbad, CA, USA). Total RNA was dissolved in elution buffer (10 $\mathrm{mM}$ Tris) and quantified using a Nanodrop 1000 spectrophotometer Thermo Scientific (Saveen Werner ApS, Denmark). Equal amounts of RNA were reverse transcribed using the High Capacity Reverse Transcription kit (Applied Biosystems, Foster City, CA) according to manufactures protocol. qPCR was performed in triplicate on $10 \mu \mathrm{L}$ reactions containing $15 \mathrm{ng}$ of cDNA and SYBR green master mix (Applied Biosystems, Carlsbad, CA, USA) using 384-well plates loaded on an ABI-PRISM 7900 Sequence Detection system (Applied Biosystems, Foster City, CA), with 40 cycles (two steps: $95^{\circ} \mathrm{C}$ for $15 \mathrm{~s}$ followed by $60^{\circ} \mathrm{C}$ for $30 \mathrm{~s}$ ). Standard curves and dissociation curves for each primer set were done to ensure for equal efficiencies and single product formation. Primer sequences are listed in table 1. IL-6 and TNF cDNA were amplified using molecular primer/probe assays with the TaqManH Universal PCR Master Mix (Applied Biosystems, Branchburg, NJ, US) and normalised to an $18 \mathrm{~S}$ pre-developed Taqman assay from Applied Biosystems, Branchburg, NJ, US (catalog \# 4310893E) as previously described [3] and all other genes were normalised to $18 \mathrm{~S}$ SYBR as previously described [11]. The $18 \mathrm{~S}$ values showed no difference between the groups in the two analysis techniques. Genes of interest were normalised to $18 \mathrm{~S}$ using the $2-\Delta \Delta \mathrm{Ct}$ method (User Bulletin No. 2, ABI PRISM 7700 Sequence Detection System) [12] and was used to calculate the relative changes in mRNA abundance.

\section{Statistical analysis}

Data for subject characteristics (age, body mass index BMI, fasting glucose, HbA1c, HOMA2-IR) are presented as mean and 95\% confidence interval $(95 \% \mathrm{CI})$. A one-way ANOVA was performed for the between-group comparisons (patients with T2DM vs. control subjects) at baseline. Between-group variation over time were analyzed with a two-way ANOVA for longitudinal measurements (SAS 9.1 proc mixed) investigating the effect of time (hours post LPS), the effect of diabetes, and the effect of time in interaction with diabetes on the outcome variable. A correlation was performed (GraphPad Prism) to calculate the relation between HOMA2-IR and baseline glucose levels to delta gene expression changes (from baseline and 4 hours post LPS). Models were fitted by backward regression, and goodness-of-fit was assessed by evaluating the distribution of the residuals. Dunnettadjusted post-hoc $t$-tests were performed if the ANOVA indicated a significant effect of time, in order to identify significant differences from baseline. $\mathrm{P}<0.05$ was considered statistically significant, in the post-hoc $t$-tests. 


\section{Results}

\section{Subject characteristics}

Baseline characteristics of the participants are shown in table 2. Patients with T2DM had higher baseline levels of fasting plasma glucose, HOMA2-IR and $\mathrm{HbA} 1 \mathrm{c}$ and lower $\mathrm{VO}_{2 \max }(\mathrm{p}<0.05)$, but were otherwise comparable to control subjects.

\section{The adipose tissue cytokine expression increases after LPS}

At baseline there were no differences in the expression of TNF and IL- 6 between patients and controls. After LPS administration, both groups demonstrated increased TNF and IL-6 expression in adipose tissue (Figures 1A and 1B), but with no difference between groups.

\section{Adipose tissue from patients with T2DM is resistant to LPS induced increases in lipolytic gene expression}

The expression of LPL, HSL and FASN were not different between the two groups at baseline. LPS administration increased adipose tissue gene expression of the lipolytic proteins, LPL and HSL in healthy controls, but not in patients with T2DM (Figures 1C and 1D). In contrast, there was no effect of LPS on the expression of the lipogenic marker, Fatty Acid Synthase in either group (FASN) (Figure 1E).

\section{Adipose tissue from patients with T2DM is resistant to LPS induced increases in adiponectin expression}

There was no difference between the expression of adiponectin and PPAR $\gamma$ between groups at baseline. Adiponectin expression increased in the control subjects, but not in patients with T2DM after LPS administration (Figure 1F). However, despite this difference in gene expression, there was no difference in serum levels of adiponectin between groups in response to LPS (data not shown). Moreover, there was no effect of LPS administration on the expression of PPAR $\gamma$, an adipogenic transcription factor that increases the expression of adiponectin (Figure 1G).

\section{FFA levels in plasma}

Based on the mRNA data, we hypothesized that we would detect a more pronounced LPS-induced increase in plasma FFA levels in control subjects compared to patients with T2DM. However, although LPS increased plasma FFA in both groups, there was no difference between groups (Figure 2). The relation between LPS-induced gene expressions changes to insulin resistance and glucose levels, respectively. The affect of LPS on gene expression changes was defined as delta fold change in gene expression from baseline and 4 hours post LPS administration for HSL, LPL and adiponectin. Both HOMA2-IR and baseline glucose levels for each subject was respectively related to the delta fold change in gene expression. There were no significant correlations between either insulin resistances (HOMA2-IR) $(\mathrm{P}>0.5)$ or glucose levels $(\mathrm{P}>0.5)$ to the delta change in gene expression of HSL, LPL or adiponectin from baseline to 4 hours post LPS administration.

\section{Discussion}

The present study showed that subcutaneous adipose tissue from patients with T2DM exhibits an altered metabolic response to a proinflammatory stimulus when compared to that from non-diabetic controls. Although a bolus of LPS elicited an increase in TNF and IL-6, both in the control and the T2DM group, the adipose tissue in patients with T2DM appeared to be resistant to activation of lipolytic genes as well as adiponectin.

The intravenous infusion of LPS is a well-characterized model to

\begin{tabular}{|l|l|l|}
\hline Gen & Primer Sequence & Probe \\
\hline $18 s$ & $\begin{array}{l}\text { Fwd 5' GCAATTATTCCCCATGAACG 3' } \\
\text { Rev 5' GGCCTCACTAAACCATCCAA 3' }\end{array}$ & \\
\hline TNF & $\begin{array}{l}\text { Fwd 5' GGAGAAGGGTGACCGACTCA 3' } \\
\text { Rev 5' TGCCCAGACTCGGCAAAG 3' }\end{array}$ & CGCTGAGATCAATCGGCCCGACTA \\
\hline IL-6 & $\begin{array}{l}\text { Fwd 5' CCAGGAGCCCAGCTATGAAC 3' } \\
\text { Rev 5' CCCAGGGAGAAGGCAACTG 3' }\end{array}$ & CCTTCTCCACAAGCGCCTTCGGT \\
\hline LPL & $\begin{array}{l}\text { Fwd 5' CCATGGCTGGACGGTAACAGGA 3' } \\
\text { Rev 5' GCCCGCGGACACTGGGTAAT 3' }\end{array}$ & \\
\hline HSL & $\begin{array}{l}\text { Fwd 5' CTCAGTGTGCTCTCCAAGTG 3' } \\
\text { Rev 5' CACCCAGGCGGAAGTCTC 3' }\end{array}$ & \\
\hline FASN & $\begin{array}{l}\text { Fwd 5' TGGTCACGGACGATGACCGTC 3' } \\
\text { Rev 5' GGTTGATGCCTCCGTCCACGAT 3' }\end{array}$ & \\
\hline Adiponectin & $\begin{array}{l}\text { Fwd 5' AAAACCTCCCCCAAGCAGAGCTTC 3' } \\
\text { Rev 5' TGAGGAACAGGGATGAGTTCAGCA 3' }\end{array}$ & \\
\hline PPARY & $\begin{array}{l}\text { Fwd 5' CTTATCTATGACAGATGTGATCTT 3' } \\
\text { Rev 5' GCTGGTCGATATCACTGGAGA 3' }\end{array}$ & \\
\hline
\end{tabular}

Table 1: qPCR Primer sequences.

\begin{tabular}{|c|c|c|c|c|c|}
\hline Baseline & $\begin{array}{l}\text { T2DM }(n=12) \\
\text { Mean }\end{array}$ & $95 \% \mathrm{Cl}$ & $\begin{array}{l}\text { Contr } \\
\text { Mean }\end{array}$ & $95 \% \mathrm{Cl}$ & P-values \\
\hline Median Age & 56.2 & $48-65$ & 58 & $52-65$ & NS \\
\hline BMI & 29.4 & $25-34$ & 27.7 & $24.7-30.7$ & NS \\
\hline $\mathrm{HbA1c}(\%)$ & 8.1 & $6.5-9.7$ & 5.7 & $5.4-6.0$ & 0.003 \\
\hline Fasting plasma glucose $(\mathrm{mmol} / \mathrm{l})$ & 11.5 & $8,6-14,4$ & 5.5 & $5,1-5,9$ & 0.0002 \\
\hline $\begin{array}{l}\mathrm{VO}_{2} \mathrm{max} / \mathrm{kg} \\
\left(\mathrm{ml} \mathrm{kg}^{-1} \mathrm{~min}^{-1}\right)\end{array}$ & 19.6 & $16.4-22,8$ & 37.3 & $28.6-45.9$ & 0.004 \\
\hline $\mathrm{FFA}(\mu \mathrm{mol} / \mathrm{L})$ & 578 & $466-690$ & 477 & $388-567$ & NS \\
\hline HOMA2-IR & 2.2 & $1.1-3.2$ & 1.0 & $0.8-1.2$ & $<0.0001$ \\
\hline
\end{tabular}

Subjects are age-matched males from a larger cohort [2]. Data are presented as means and $95 \%$ confidence intervals $(95 \% \mathrm{Cl})$

Table 2: Subject characteristics. 


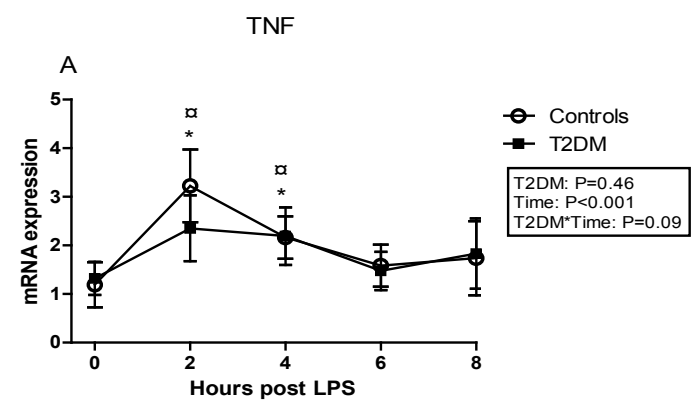

IL-6
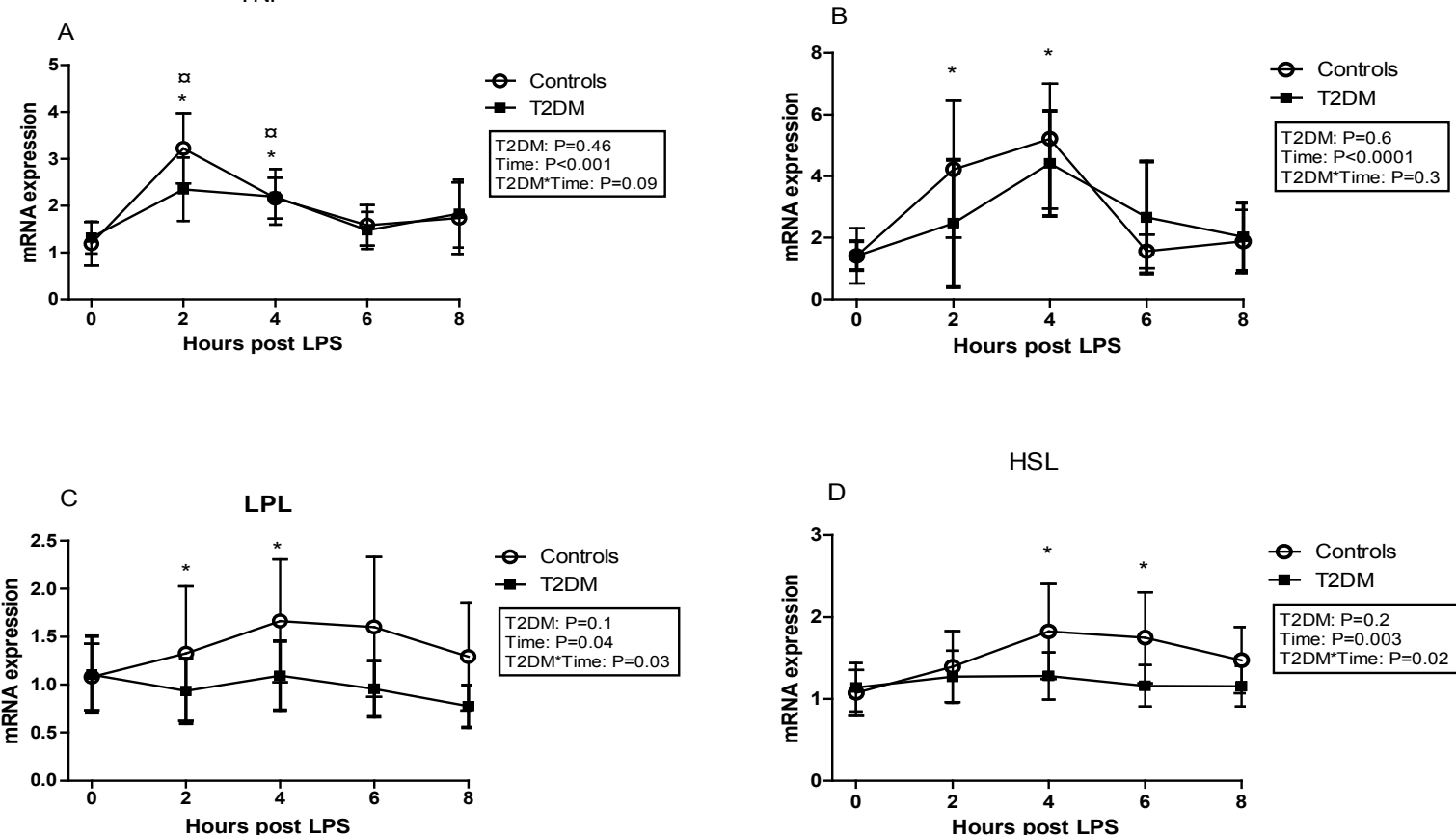

HSL

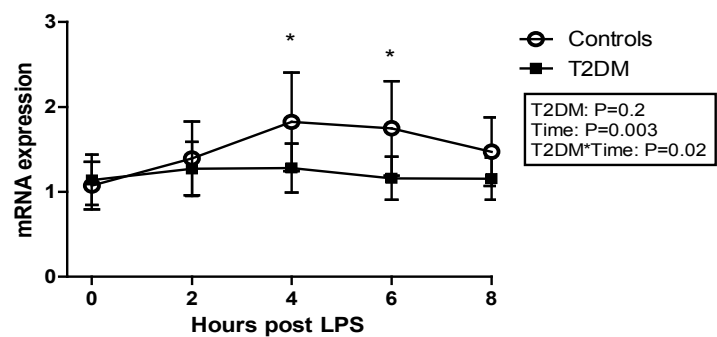

FASN
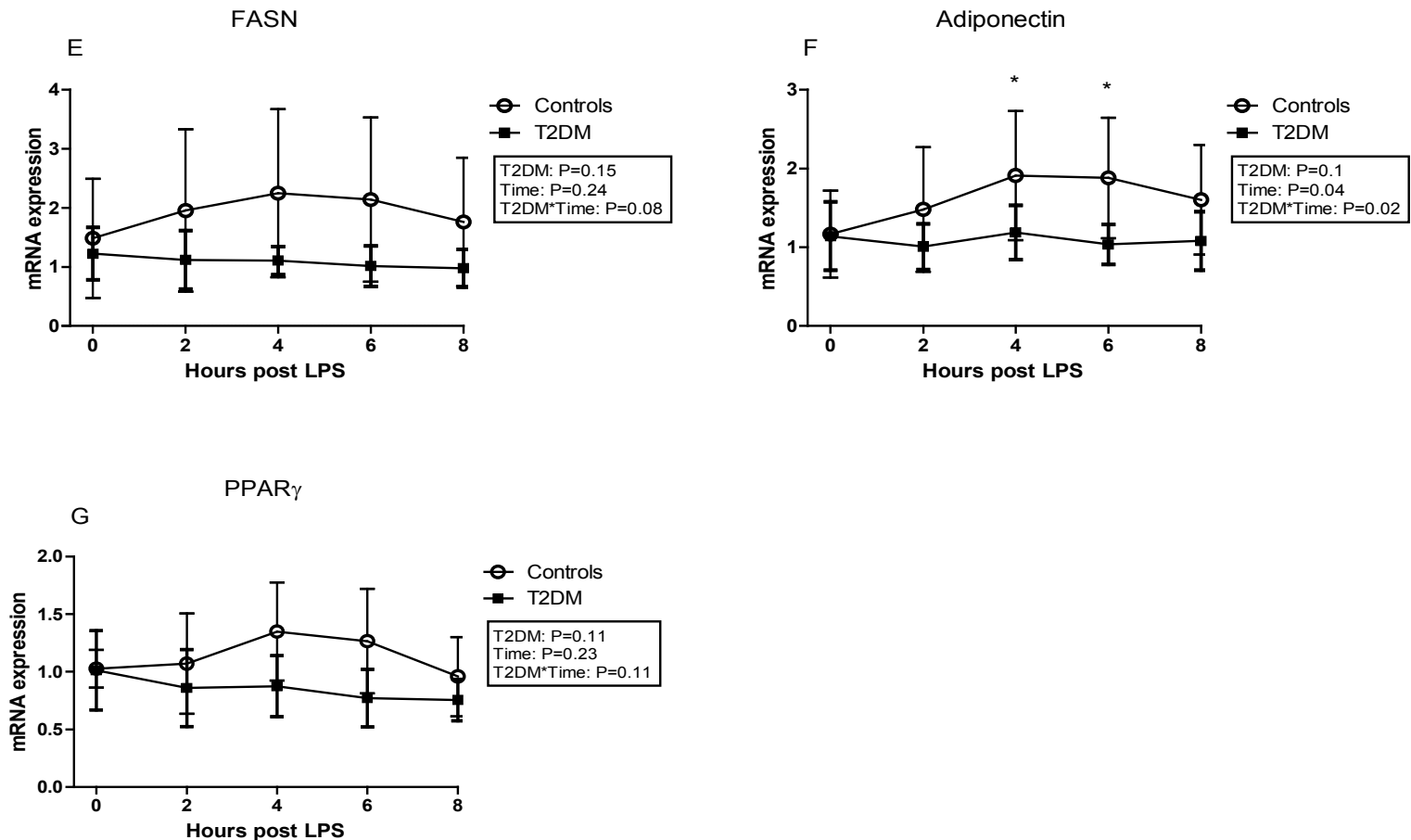

Figure 1: A-G: TNFa, IL-6 LPL, HSL, FASN, adiponectin and PPARy mRNA levels in adipose tissue after LPS administration.

a. Fold changes (mean and 95\% confidenceintervals) from baseline in mRNA gene expression of TNFa

b. IL-6, C) LPL, D) HSL, E) FASN, F) Adiponectin, G) PPARY

in abdominal subcutaneous adipose tissue biopsies obtained immediately before, 2; $4 ; 6$ and 8 hours following LPS administration (0.3 ng/kg) in 12 volunteers with type 2 diabetes (T2DM) (filled squares) and 12 controls (open circles). A two-way ANOVA was used to assess the main effect of time, group and their interaction (Time*Group). If a significant effect of time was found, a post-hoc $t$ test was applied whereby * indicates $P<0.05$ in controls and indicates $P<0.05$ in patient with T2DM when comparing each time point after LPS with baseline. 


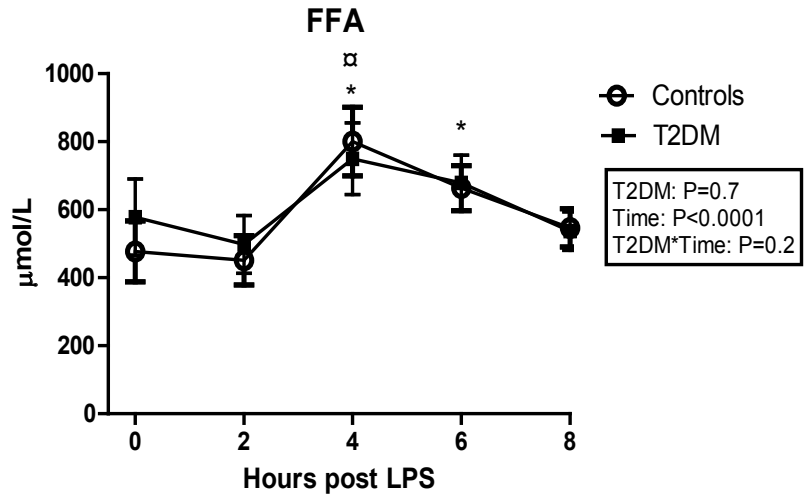

Figure 2: Free fatty acid (FFA) levels in plasma measured immediately before and during the 8 hours following LPS administration $(0.3 \mathrm{ng} / \mathrm{kg})$ in 12 patients with T2DM (filled squares) and 12 controls (open circles). Data are presented as $\mu \mathrm{mol} / \mathrm{L}$ and $95 \%$ confidence interval. A two-way ANOVA was used to assess the main effect of time, group and their interaction (Time*Group). A significant main effect of time was found and a post-hoc $t$ test was applied whereby * indicates $p<0.05$ in controls and indicates $P<0.05$ in patients with T2DM versus time point $0 \mathrm{hr}$.

study systemic inflammation and immune response, inducing cytokine release and pathway activation at virtually no risk to participants [13]. LPS administration is known to elicit lipolysis in adipocyte cell cultures as well as healthy humans $[14,15]$, and lipolysis is similarly enhanced during sepsis and acute inflammation [16]. This may be triggered directly by LPS or indirectly by circulating cytokines [14,16-18].

Circulating LPS have previously been demonstrated in subjects without notable infection and in patients with T2DM $[19,20]$. It is possible that such chronic low-grade exposure to LPS may induce LPS tolerance, and thus explain the blunted response to LPS administration seen in patients with T2DM [21]. LPS tolerance has been suggested to involve epigenetic modifications that increase promoter methylation of pro-inflammatory cytokines, such as TNF- $\alpha$ [22]. This assertion is consistent with previously published data from a larger cohort, which showed that patients with T2DM fail to increase plasma levels of cytokines to a similar extent to that of control subjects in response to LPS [2]. The similar increase of LPS-induced expression of adipose tissue TNF and IL-6 observed in the present study may, however, suggest that patients with T2DM are not resistant to all effects of LPS. Hence, the expression of TNF and IL-6 in skeletal muscle tissue has previously been found to exhibit similar increases in patients with T2DM and control subjects in response to LPS [3]. One putative explanation is that the plasma cytokine response is principally elicited by intravascular immune cells, such as mono- and lymphocytes, which may be rendered tolerant by the chronically elevated plasma LPS levels in T2DM. In contrast, these very low levels of intravascular LPS may not affect skeletal muscle and subcutaneous adipose tissue, which therefore retain their ability to mount an inflammatory response to LPS.

In the present study, a peak increase in the expression of TNF in adipose tissue was observed 2 hours after LPS administration, in accordance with the observation that systemic circulating plasma levels of TNF peak at the same time point post LPS $[2,23,24]$. The expression of the lipolytic markers, HSL and LPL, peaked 4 hours after LPS administration in subcutaneous adipose tissue in controls, suggesting a possible effect by systemic and/or local cytokines on lipolysis. We observed that the increase in HSL and LPL gene expression was blunted in patients with T2DM, suggesting an inability of the diabetic adipose tissue to respond to LPS-induced metabolic challenge to the body. Thus, during sepsis and acute inflammation, an immediate increase in plasma FFA may act as a response to mobilize energy needed for the host to combat inflammation [25].

In contrast to other studies reporting a reduced lipolytic activity [26] and lower expression of HSL in subcutaneous adipose tissue from patients with insulin resistance and obese subjects $[27,28]$, we found a similar mRNA expression of HSL and LPL in controls and patients with T2DM at baseline. However, we were unable to measure protein or activity levels. If LPS induced a similar increase in LPL and HSL expression, FFA could be expected to be higher in the diabetics compared to the control group, which was not the case; however, after LPS, FFA levels increased to a similar extent in both groups. We speculate, first, that other fat depots in the body may have been responsible for the increase in FFA levels after LPS in the diabetic group. Thus, while the abdominal subcutaneous fat depot is usually considered the main source of FFA into plasma [29], a small proportion arises from leg and intra-abdominal adipose tissue [30-32]. Secondly, we propose that the attenuated LPL and HSL expression response in the subcutaneous adipose tissue in patients with T2DM encompasses compensatory mechanism that serves to limit the systemic levels of FFA upon pro-inflammatory stimuli. Lastly, lipolysis driven by HSL, which is regulated either by induction of gene expression or by alteration in its phosphorylation state [6], may be more sensitive to phosphorylated HSL or thus compensate for the lack of response in gene expression in T2DM.

The mechanisms behind the blunted LPS stimulated metabolic response in patients with $\mathrm{T} 2 \mathrm{DM}$ are not fully understood. In the present study, insulin resistance or high glucose levels do not seem to affect the LPS-resistance observed in patients with T2DM, as LPSinduced changes in gene expression of HSL, LPL and adiponectin were not related to HOMA2-IR or glucose. However, further studies are necessary to fully investigate these responses in model systems.

In vitro studies have shown that catecholamines induce lipolysis in adipocytes; furthermore, preadipocytes isolated from obese subjects have significantly reduced HSL gene expression, suggesting that obesity is associated with an impaired intrinsic lipolytic activity $[26,33,34]$. As an alternative explanation, we cannot exclude a possible drug-induced anti-lipolytic effect in the T2DM subjects, even though they had stopped their anti-diabetic medication one week prior to the study. For example, a recent cell culture study showed that the antidiabetic drug, metformin, reduces lipolysis stimulated by LPS and TNF in human adipocytes via HSL [35]. Moreover, the expression of HSL has been related to the degree of lipolysis in human fat cells [36] Finally, alternative lipolytic pathways may be activated in patients with T2DM; hence, HSL deficient mice were lean and resistant to genetic and diet-induced obesity, indicating that other lipases were involved in controlling the mobilization of fatty acids from fat depots $[37,38]$.

\section{Adiponectin}

Although studies show that adiponectin levels are decreased in obese and T2DM patients [39], we found no such difference between control and T2DM subjects at baseline. In response to LPS, the expression of adiponectin increased in controls, but not in patients with T2DM; this finding in control subjects, as well as the finding that plasma adiponectin levels were unchanged after LPS, is supported by previous studies $[23,24]$. The adipose expression of adiponectin was increased, and plasma levels remained relatively constant in control subjects. With regard to the expression of PPAR $\gamma$, we found the same 
trend as adiponectin, although not statistically significant. PPAR $\gamma$ is usually considered a major transcriptional activator of adiponectin [40]; the absence of an increase in the mRNA of this enzyme may thus be due to a type 2 statistical error, or, alternatively, additional activators may exist. In the present study, we hypothesized that patients with T2DM would display an attenuated increase in gene expression of lipogenic mediators within adipose tissue following LPS administration. As an insulin sensitizing and anti-inflammatory hormone, the increased expression of adiponectin in adipose tissue of control subjects may represent a compensatory mechanism to counteract insulin resistance during an inflammatory stimulus. However, patients with T2DM do not appear to be able to respond adequately to the metabolic effects of inflammation by increasing expression of adiponectin, which may have implications for the degree of insulin resistance during an acute inflammation.

\section{Conclusion}

In conclusion, patients with T2DM demonstrate an attenuation of LPS-induced metabolic changes in adipose tissue, which is compatible with an impaired homeostatic reaction to a pro-inflammatory stimulus. This reduced response may cause dysmetabolic changes as part of a complex pattern of pathophysiological mechanisms that contribute to the poor prognosis associated with infection in patients with T2DM.

\section{Acknowledgements}

Lone Peijs, Ruth Rousing and Hanne Villumsen are acknowledged for their technical assistance. The Centre of Inflammation and Metabolism (CIM) is supported by a grant from the Danish National Research Foundation (\# 02-51255). This study was further supported in part by the Danish Council for Independent Research - Medical Sciences, the Commission of the European Communities (Grant Agreement no. 223576 - MYOAGE), and in part by grants from The Beckett Foundation, The Larsen Foundation, The Foundation of Brdr. Hartmann, The Foundation of Direktor Emil Hertz og Hustru Inger Hertz, The A.P. Moller Foundation, The Foundation of The Danish Diabetes Association, The Lærda Foundation, and the Foundation of Kong Christian den Tiende, P. Carl Petersens Fond, Illum Fondet, Max og Anna Friedmanns legat til sygdomsbekæmpelse Direktør Jacob Madsen og hustru Olga Madsens fond. CIM is part of the UNIK Project: Food, Fitness and Pharma for Health and Disease, supported by the Danish Ministry of Science, Technology, and Innovation. CIM is a member of DD2 - the Danish Center for Strategic Research in Type 2 Diabetes (the Danish Council for Strategic Research, grant no. 09-067009 and 09-075724). The Copenhagen Muscle Research Centre is supported by a grant from the Capital Region of Denmark.

\section{References}

1. Shah BR, Hux JE (2003) Quantifying the risk of infectious diseases for people with diabetes. Diabetes Care 26: 510-513.

2. Andreasen AS, Pedersen-Skovsgaard T, Berg RM, Svendsen KD, FeldtRasmussen B, et al. (2010) Type 2 diabetes mellitus is associated with impaired cytokine response and adhesion molecule expression in human endotoxemia. Intensive Care Med 36: 1548-1555.

3. Andreasen AS, Kelly M, Berg RM, Moller K, Pedersen BK (2011) Type 2 diabetes is associated with altered NF- KB DNA binding activity, JNK phosphorylation, and AMPK phosphorylation in skeletal muscle after LPS. PLoS One 6: e23999.

4. Scherer PE (2006) Adipose tissue: from lipid storage compartment to endocrine organ. Diabetes 55: 1537-1545.

5. Trayhurn P (2007) Adipocyte biology. Obes Rev 8: 41-44.

6. Khovidhunkit W, Kim MS, Memon RA, Shigenaga JK, Moser AH, et al. (2004) Effects of infection and inflammation on lipid and lipoprotein metabolism: mechanisms and consequences to the host. J Lipid Res 45: 1169-1196.

7. Krogh-Madsen R, Plomgaard P, Akerstrom T, Moller K, Schmitz O, et al. (2008) Effect of short-term intralipid infusion on the immune response during low-dose endotoxemia in humans. Am J Physiol Endocrinol Metab 294: E371-E379.

8. Meijer K, de Vries M, Al-Lahham S, Bruinenberg M, Weening D, et al. (2011) Human primary adipocytes exhibit immune cell function: adipocytes prime inflammation independent of macrophages. PLoS One 6: e17154.
9. WHO (2006) Definitions and Diagnosis of Diabetes Mellitus and Intermediate Hyperglycemia.

10. Taudorf S, Krabbe KS, Berg RM, Pedersen BK, Moller K (2007) Human models of low-grade inflammation: bolus versus continuous infusion of endotoxin. ClinVaccine Immunol 14: 250-255.

11. Guan H, Yang K (2008) RNA isolation and real-time quantitative RT-PCR. Methods Mol Biol 456: 259-270.

12. Livak KJ, Schmittgen TD (2001) Analysis of relative gene expression data using real-time quantitative PCR and the 2(-Delta Delta $\mathrm{C}(\mathrm{T})$ ) Method. Methods 25: 402-408.

13. Andreasen AS, Krabbe KS, Krogh-Madsen R, Taudorf S, Pedersen BK, et al (2008) Human endotoxemia as a model of systemic inflammation. Curr Med Chem 15: 1697-1705.

14. Grisouard J, Bouillet E, Timper K, Radimerski T, Dembinski K, et al (2010) Both inflammatory and classical lipolytic pathways are involved in lipopolysaccharides-induced lipolysis in human adipocytes. Innate Immun 18: $25-34$

15. Krogh-Madsen R, Moller K, Dela F, Kronborg G, Jauffred S, et al. (2004) Effect of hyperglycemia and hyperinsulinemia on the response of IL-6, TNF-alpha, and FFAs to low-dose endotoxemia in humans. Am J Physiol Endocrinol Metab 286: E766-E772

16. Memon RA, Feingold KR, Moser AH, Fuller J, Grunfeld C (1998) Regulation of fatty acid transport protein and fatty acid translocase mRNA levels by endotoxin and cytokines. Am J Physiol 274: E210-E217.

17. Bes-Houtmann S, Roche R, Hoareau L, Gonthier MP, Festy F, et al. (2007) Presence of functional TLR2 and TLR4 on human adipocytes. Histochem Cell Biol 127: 131-137.

18. Feingold KR, Staprans I, Memon RA, Moser AH, Shigenaga JK, et al (1992) Endotoxin rapidly induces changes in lipid metabolism that produce hypertriglyceridemia: low doses stimulate hepatic triglyceride production while high doses inhibit clearance. J Lipid Res 33: 1765-1776.

19. Creely SJ, McTernan PG, Kusminski CM, Fisher M, da Silva NF, et al. (2007) Lipopolysaccharide activates an innate immune system response in human adipose tissue in obesity and type 2 diabetes. Am J Physiol Endocrinol Metab 292: E740-E747.

20. Cani PD, Delzenne NM (2009) The role of the gut microbiota in energy metabolism and metabolic disease. Curr Pharm Des 15: 1546-1558.

21. Kox M, de Kleijn S, Pompe JC, Ramakers BP, Netea MG, et al. (2011) Differential ex vivo and in vivo endotoxin tolerance kinetics following human endotoxemia. Crit Care Med 39: 1866-1870.

22. El Gazzar M, Yoza BK, Hu JY, Cousart SL, McCall CE (2007) Epigenetic silencing of tumor necrosis factor alpha during endotoxin tolerance. $\mathrm{J}$ Biol Chem 282: 26857-26864.

23. Anderson PD, Mehta NN, Wolfe ML, Hinkle CC, Pruscino L, et al. (2007) Innate immunity modulates adipokines in humans. J Clin Endocrinol Metab 92: 2272 2279

24. Keller P, Moller K, Krabbe KS, Pedersen BK (2003) Circulating adiponectin levels during human endotoxaemia. Clin Exp Immunol 134: 107-110.

25. Lind L, Lithell H (1994) Impaired glucose and lipid metabolism seen in intensive care patients is related to severity of illness and survival. Clin Intensive Care 5: 100-105.

26. Large V, Reynisdottir S, Langin D, Fredby K, Klannemark M, et al. (1999) Decreased expression and function of adipocyte hormone-sensitive lipase in subcutaneous fat cells of obese subjects. J Lipid Res 40: 2059-2066.

27. Jocken JW, Langin D, Smit E, Saris WH, Valle C, et al. (2007) Adipose triglyceride lipase and hormone-sensitive lipase protein expression is decreased in the obese insulin-resistant state. J Clin Endocrinol Metab 92: 2292-2299.

28. Langin D, Arner P (2006) Importance of TNFalpha and neutral lipases in human adipose tissue lipolysis. Trends Endocrinol Metab 17: 314-320.

29. Eaton RP, Berman M, Steinberg D (1969) Kinetic studies of plasma free fatty acid and triglyceride metabolism in man. J Clin Invest 48: 1560-1579.

30. Arner $P(2002)$ Insulin resistance in type 2 diabetes: role of fatty acids. Diabetes Metab Res Rev 18: S5-S9. 
Citation: Mathur N, Andreasen AS, Berg RMG, Pedersen M, Møller K, et al. (2012) Altered Subcutaneous Adipose Tissue Response to Systemic LPS Administration in Patients with Type 2 Diabetes. J Diabetes Metab 3: 217. doi:10.4172/2155-6156.1000217

31. Karpe F, Dickmann JR, Frayn KN (2011) Fatty acids, obesity, and insulin resistance: time for a reevaluation. Diabetes 60: 2441-2449.

32. Nielsen S, Guo Z, Johnson CM, Hensrud DD, Jensen MD (2004) Splanchnic lipolysis in human obesity. J Clin Invest 113: 1582-1588.

33. Arner $P$, Langin $D(2007)$ The role of neutral lipases in human adipose tissue lipolysis. Curr Opin Lipidol 18: 246-250.

34. Langin D, Dicker A, Tavernier G, Hoffstedt J, Mairal A, et al. (2005) Adipocyte lipases and defect of lipolysis in human obesity. Diabetes 54: 3190-3197.

35. Grisouard J, Timper K, Bouillet E, Radimerski T, Dembinski K, et al. (2011) Metformin counters both lipolytic/inflammatory agents-decreased hormone sensitive lipase phosphorylation at Ser-554 and -induced lipolysis in human adipocytes. Arch Physiol Biochem 117: 209-214.
36. Large V, Arner P, Reynisdottir S, Grober J, van H, et al. (1998) Hormonesensitive lipase expression and activity in relation to lipolysis in human fat cells. J Lipid Res 39: 1688-1695.

37. Haemmerle G, Zimmermann R, Zechner R (2003) Letting lipids go: hormonesensitive lipase. Curr Opin Lipidol 14: 289-297.

38. Harada K, Shen WJ, Patel S, Natu V, Wang J, et al. (2003) Resistance to highfat diet-induced obesity and altered expression of adipose-specific genes in HSL-deficient mice. Am J Physiol Endocrinol Metab 285: E1182-E1195.

39. Funahashi T, Matsuzawa $Y$ (2006) Hypoadiponectinemia: a common basis for diseases associated with overnutrition. Curr Atheroscler Rep 8: 433-438.

40. Sharma AM, Staels B (2007) Review: Peroxisome proliferator-activated receptor gamma and adipose tissue--understanding obesity-related changes in regulation of lipid and glucose metabolism. J Clin Endocrinol Metab 92: 386395. 